\title{
A influência dos ativos intangíveis na relevância da informação contábil
}

The influence of intangible assets in the relevance of accounting information

La influencia de activos intangibles en la importancia de la información contable

\author{
Alini da Silva \\ Doutoranda em Ciências Contábeis e Administração na \\ Universidade Regional de Blumenau (FURB) \\ Endereço: Rua Antônio da Veiga, 140 - Bairro Itoupava Seca \\ PPGCC sala D-202 - Campus I, Universidade Regional de Blumenau \\ CEP: 89030-903 - Blumenau/SC - Brasil \\ E-mail: alinicont@gmail.com \\ Telefone: (47) 3321-0565 \\ Taciana Rodrigues de Souza \\ Doutoranda em Ciências Contábeis na \\ Universidade do Vale do Rio dos Sinos (UNISINOS) \\ Endereço: Av. Unisinos, 950 \\ Programa de Pós-Graduação em Ciências Contábeis, Caixa Postal 275 \\ CEP: 93022-750 - São Leopoldo/ RS - Brasil. \\ E-mail: taciana.rodrigues.souza@gmail.com \\ Telefone: (51) 3590-8186

\section{Roberto Carlos Klann} \\ Doutor em Ciências Contábeis e Administração na \\ Universidade Regional de Blumenau (FURB) \\ Professor no Programa de Pós-Graduação em Ciências Contábeis na \\ Universidade Regional de Blumenau (FURB) \\ Endereço: Rua Antônio da Veiga, 140 - Bairro Itoupava Seca \\ PPGCC sala D-202 - Campus I, Universidade Regional de Blumenau \\ CEP: 89030-903 - Blumenau/SC - Brasil \\ E-mail: rklann@furb.br \\ Telefone: (47) 3321-0565
}

Artigo recebido em 05/03/2015. Revisado por pares em 01/08/2016. Reformulado em 08/12/2016. Recomendado para publicação em 15/01/2017 por Carlos Eduardo Facin Lavarda (Editor-Chefe). Publicado em 30/04/2017. 


\title{
Resumo
}

O objetivo do presente estudo foi analisar a influência dos ativos intangíveis na relevância da informação contábil. A metodologia utilizada caracterizou-se como descritiva, documental e quantitativa. A amostra do estudo constituiu-se de 164 empresas listadas na BM\&FBOVESPA, no período de 2010 a 2013. A análise das informações foi realizada por meio de regressão de dados em painel, com a utilização dos softwares STATA e SPSS. Os resultados apontaram que lucro líquido, patrimônio líquido, ativo intangível, goodwill, patrimônio líquido ajustado e lucro líquido ajustado são informações relevantes para o mercado de capitais, as quais impactam no preço das ações até 6 (seis) meses depois de publicadas as demonstrações financeiras. Esses resultados revelam a importância para o mercado de capitais das informações contábeis ora apresentadas, tanto as tradicionais - como lucro líquido e patrimônio líquido - quanto as relacionadas aos ativos intangíveis. Tais informações contábeis demonstraram-se relevantes para os investidores decidirem na compra e venda de ações. Desta forma, infere-se a necessidade das empresas divulgarem seus ativos intangíveis, uma vez que tal prática pode contribuir para o aumento do preço de suas ações no mercado de capitais.

Palavras-chave: Valor relevante; Informação contábil; Ativos intangíveis

\begin{abstract}
The study aims to analyze the intangible asset influences on the accounting information relevance. The methodology used was characterized as descriptive, documentary and quantitative. The study sample consisted of 164 companies listed on BM\&FBOVESPA, from 2010 to 2013. The information analysis was performed using panel data regression, using STATA and SPSS software. The results showed that the net income, net assets, intangible assets, goodwill, adjusted equity and adjusted net income are relevant information to the capital markets, which impact the stock price up to six months after the financial statement publications. These results reveal the accounting information importance presented herein, both traditional and net income and shareholders' equity, as well as those related to intangible assets, for the capital market. Such accounting information has proved to be relevant for investors to decide on the share purchases and sales. In this way, it is inferred the need for companies to disclose their intangible assets for them to contribute to the increasing price of their shares in the capital market.
\end{abstract}

Keywords: Relevant value; Accounting information; Intangible assets

\section{Resumen}

El objetivo de este estudio fue analizar la influencia de los activos intangibles en la relevancia de la información contable. La metodología utilizada se caracteriza por ser descriptiva, documental y cuantitativo. La muestra del estudio consistió en 164 empresas en la BM\&FBOVESPA, en el periodo comprendido entre 2010 y 2013. Se realizó el análisis de la información mediante regresión de datos de panel, con el uso de STATA y SPSS. Los resultados mostraron que el ingreso neto, los activos netos, activos intangibles, fondo de comercio, capital ajustado y el ingreso neto ajustado son información relevante a los mercados de capitales, que repercuten en el precio de las acciones de hasta seis meses después de la publicación de los estados financieros.

Palabras clave: Valor relevante; Información contable; Los activos intangibles

\section{Introdução}

As demonstrações contábeis são úteis aos usuários quando fornecem informações relevantes. Os estudos que investigam a relevância das informações contábeis podem ser 
denominados de estudos sobre value relevance (SILVA; MACEDO; MARQUES, 2012). A busca por novos mercados e a competição existente entre as empresas tornam as informações contábeis essenciais para os tomadores de decisão devido ao fornecimento de informações financeiras relevantes (IUDÍCIBUS, 2000).

De acordo com Ball e Brown (1968) e Beaver (1968), o mercado de capitais é eficiente e imparcial, no qual as informações contábeis são úteis para formar o preço das ações. Deste modo, o mercado de capitais ajusta os preços das ações rapidamente de acordo com as informações disponíveis das empresas (BALL; BROWN, 1968).

O exame do comportamento dos preços das ações auxilia no entendimento do comportamento dos investidores das organizações que, por sua vez, fornecem informações relevantes aos gestores das empresas e órgãos de normatização. A relevância da informação contábil reflete o consenso de investidores sobre os preços das ações, representada pela associação entre o valor contábil de um ativo com o preço das ações no mercado de capitais (BARTH; BEAVER; LANDSMAN, 2001).

A relação significativa entre as informações contábeis relevantes e confiáveis com o preço das ações interfere no posicionamento dos investidores quanto ao interesse dispendido à empresa (FASB, 1984). Quando uma informação é relevante, ela fornece dados novos que afetam a expectativa de desempenho futuro da empresa, interferindo na tomada de decisão de usuários em relação à compra ou à venda de ações que, por sua vez, afeta a criação de valor da empresa (ANTUNES et al., 2010).

A criação de valor de uma organização é relacionada de forma direta com os ativos intangíveis, que são responsáveis pela geração de valor aos usuários e também pelo aumento no desempenho financeiro da empresa (PEREZ; FAMÁ, 2006). Para Kayo et al. (2006), a soma dos ativos tangíveis e intangíveis resulta no valor econômico de uma organização. Entretanto, os ativos intangíveis destacaram-se, nos últimos anos, pelo aumento de sua importância na geração de valor organizacional, o que contribui para obter vantagens competitivas.

Diante deste contexto, apresenta-se a questão que norteia a presente pesquisa: qual a influência dos ativos intangíveis na relevância da informação contábil? Deste modo, a fim de responder ao problema da pesquisa, cumpre analisar a influência dos ativos intangíveis na relevância da informação contábil.

Estudos nacionais e internacionais investigaram a relação existente entre os ativos intangíveis e a criação de valor da empresa no mercado, tanto para os acionistas como em relação à rentabilidade empresarial. No que se refere ao âmbito nacional, Perez e Famá (2006) investigaram o impacto dos ativos intangíveis não contabilizados no desempenho empresarial, de modo a verificar estatisticamente a sua responsabilidade em maior geração de valor para os acionistas. Decker et al. (2013) analisaram a relação existente entre ativos intangíveis e a rentabilidade das empresas listadas na BM\&FBOVESPA, no período de 2006 a 2011.

Quanto às pesquisas internacionais, Lev e Zarowin (1999), Chalmers, Clinch e Godfrey (2008), Morricone, Oriani e Sobrero (2009), Oliveira, Rodrigues e Craig (2010) pesquisaram sobre a criação de valor dos ativos intangíveis para a empresa e o impacto da alteração de normas de contabilidade locais para IFRS. Lev e Zarowin (1999) pesquisaram sobre a utilidade das informações financeiras relacionadas aos ativos intangíveis. Chalmers, Clinch e Godfrey (2008) analisaram a relevância do valor dos intangíveis em empresas australianas entre os regimes das Normas Contábeis Internacionais (IFRS) e das normas australianas (AGAAP). Morricone, Oriani e Sobrero (2009) analisaram se a adoção obrigatória das IFRS alterou a criação de valor dos ativos intangíveis em empresas italianas no período de 1996 a 2006.

Oliveira, Rodrigues e Craig (2010) avaliaram, nas demonstrações contábeis de 1998 a 2008, o valor identificável de ativos intangíveis, o valor de ágio de todas as organizações não financeiras listadas na Bolsa de Valores Portuguesa e o impacto da adoção formal da IAS 38 e 
IFRS 3, relacionadas aos ativos intangíveis, nos preços das ações.

Desta forma, destaca-se uma lacuna de pesquisa, que consiste em analisar a criação de valor dos ativos intangíveis em empresas brasileiras no período compreendido entre 2010 a 2013, o qual se refere ao período de adoção das IFRS, comparando com os resultados dos estudos internacionais abordados. Para a realização do estudo, foram utilizados como base os modelos de regressão de Ball e Brown (1968), os quais verificaram a influência do lucro líquido e do patrimônio líquido no preço das ações, além de Morricone, Oriani e Sobrero (2009), Oliveira, Rodrigues e Craig (2010), que analisaram o efeito do goodwill, ativos intangíveis, patrimônio líquido ajustado e lucro líquido ajustado com os preços das ações.

O presente estudo também se justifica por analisar a relevância da informação contábil com informações de empresas localizadas em um país em desenvolvimento, visto que os estudos sobre este tema foram realizados em países desenvolvidos, como Itália, Portugal e Austrália.

\section{Relevância da Informação Contábil}

A qualidade da informação contábil é necessária para que tomadores de decisões possuam informações relevantes sobre as características do desempenho financeiro das empresas. A qualidade dos lucros depende das informações que as empresas divulgam sobre o desempenho empresarial e que sejam relevantes para os tomadores de decisões, tais como investidores, acionistas, entre outros. Os atributos da qualidade da informação contábil se referem à persistência dos lucros, ao conservadorismo contábil, ao gerenciamento de resultados, à qualidade dos accruals, ao nível de disclosure, à transparência das informações e à sua relevância, que representam a relação entre dados contábeis e o preço das ações ou valor de mercado das empresas (DECHOW; GE; SCHRAND, 2010).

Nos últimos anos, houve um aumento do interesse dos pesquisadores em investigar a relação existente entre os valores do mercado das ações e os números contábeis evidenciados, as normas específicas já em utilização ou propostas de novas normas. A literatura que aborda a relação entre o mercado das ações e os dados contábeis denomina-se value relevance (HOLTHAUSEN; WATTS, 2001).

Quando a contabilidade consegue mensurar e comunicar eventos econômicos e seus respectivos resultados no patrimônio da empresa, os preços das ações podem sofrer influência, visto que apresentam informações relevantes e significativas para os investidores e analistas do mercado de capitais (MACEDO; MACHADO; MACHADO, 2013). Silva, Macedo e Marques (2012) afirmam que a utilidade das demonstrações contábeis está diretamente ligada à relevância que suas informações possuem ao serem divulgadas aos usuários.

Estudos sobre value relevance investigam a relevância de determinada informação contábil para o mercado de capitais. A informação é relevante quando reflete no preço das ações (SILVA; MACEDO; MARQUES, 2012; BEISLAND; HAMBERG, 2013). Neste sentido, as informações contábeis de qualidade e relevância fornecem subsídios aos usuários das empresas por apresentarem dados novos, capazes de alterar a previsibilidade de desempenho empresarial futuro. No caso dos investidores, podem alterar as decisões relacionadas à compra ou à venda de ações. Desta forma, as informações contábeis relevantes, ou seja, que capturam as alterações de valor da empresa, possuem o poder de afetar a tomada de decisão e a capacidade preditiva da empresa (ANTUNES et al., 2010).

$\mathrm{Na}$ literatura existente, os valores contábeis, de acordo com Barth, Beaver e Landsman (2001), são definidos como relevantes se possuem associações significativas com os valores do mercado de ações. Ball e Brown (1968) destacam que a relevância da informação contábil afeta os preços das ações e as crenças dos investidores em relação às empresas. Neste mesmo sentido, 
o FASB (1984) destaca que um valor contábil é considerado relevante somente se este valor for capaz de influenciar os usuários nas decisões baseadas nas demonstrações financeiras.

\subsection{Ativos Intangíveis}

Os ativos possuem como característica principal uma promessa futura de caixa, ou seja, a capacidade de prestar serviços futuros à entidade que controla o ativo ou os fatores de produção que são capazes de transformar fluxos líquidos em entrada de caixa (IUDÍCIBUS, 2000, p. 142). De acordo com Hendriksen e Van Breda (1999), os ativos que carecem de substância física - ou seja, os ativos intangíveis - devem ser reconhecidos desde que preencham os requisitos de reconhecimento de ativo, sendo mensuráveis, relevantes e precisos.

Kaplan e Norton (1997), no final da década de 1990, já argumentavam que a contabilidade financeira deveria ampliar a incorporação da avaliação dos ativos intangíveis e intelectuais como os produtos, serviços, funcionários, habilidades, processos internos, clientes satisfeitos e fiéis. Esta avaliação mais ampla de intangível é útil às empresas de informação, visto que estes ativos são mais importantes do que os tangíveis. Os ativos intangíveis são definidos como um conjunto de conhecimentos, práticas e atitudes empresariais que interagem com outros ativos tangíveis e contribuem para a formação do valor da empresa (KAYO, 2002).

Os ativos intangíveis, também conhecidos por ativos invisíveis ou ativos intelectuais, são geralmente representados por alguns tipos específicos de ativos, tais como: patentes, franquias, marcas, goodwill, direitos autorais, processos secretos, franquias, licenças, softwares desenvolvidos, bancos de dados, concessões públicas, direitos de exploração e operação, uma carteira fiel de clientes, entre outros. Estes ativos devem possuir natureza permanente, sem existência física e que sejam capazes de produzir benefícios futuros a fim de serem enquadrados como intangíveis. A existência de somente um ativo intangível não é suficiente para que seja reconhecido nas demonstrações contábeis. Devem-se observar preceitos e normas sobre estes ativos, quando gerados internamente ou quando possuem subjetividade (PEREZ; FAMÁ, 2006).

$\mathrm{Na}$ nova economia, os ativos intangíveis são importantes e distintos entre as empresas. De acordo com o FASB, as empresas reconhecem estes ativos nas demonstrações contábeis quando adquiridos de outras empresas, ou quando atendem a diversos requisitos por outros; porém, há importância do desenvolvimento de bases para reconhecimento e mensuração dos intangíveis gerados internamente (UPTON, 2001).

De acordo com o CPC 04, para que os ativos intangíveis gerados internamente sejam reconhecidos nas demonstrações contábeis, eles devem estar na fase de desenvolvimento e não na fase de pesquisa. A fase de pesquisa de determinado ativo intangível corresponde à fase inicial do projeto, em que a empresa incorre em gastos, mas estes são relacionados ainda à fase de conhecimento daquilo que se pretende desenvolver, e de acordo com o CPC deve ser, portanto, reconhecido como despesa no período e não como ativo intangível no balanço patrimonial. Já o ativo intangível que se encontra na fase de desenvolvimento deve ter todos os seus gastos relacionados ativados em conta específica no balanço patrimonial como intangível em desenvolvimento porque esta fase é considerada como uma fase já de produção do item.

Tem-se também a figura do goodwill, o qual surge no momento da aquisição de determinados itens de empresas (seja capital ou ativos), em que a empresa que adquire paga valores a mais do que o valor do mercado dos itens adquiridos e esta diferença deve ser registrada como goodwill no balanço da empresa que está comprando. A empresa paga a mais do que o valor de mercado devido à expectativa de rentabilidade futura que ela poderá ter em decorrência da aquisição dos itens. Ainda, além do goodwill, tem-se o ágio por mais valia de ativos, o qual surge quando os itens das empresas apresentam valores de mercado maiores do 
que os registrados na contabilidade, e devem ser contabilizados no balanço patrimonial da empresa adquirente, assim como o goodwill (quando ocorrer), como uma forma de ativo intangível chamado de ágio. Tanto o goodwill quanto o ágio, que são gerados internamente por determinada empresa, só podem ser registrados quando outra empresa adquire itens patrimoniais e paga valores por isso (goodwill e ágio) (CPC 04; CPC 15).

O conceito de goodwill, além de ser contemplado por normas contábeis, é bastante discutido na literatura. De acordo com Monobe (1986), o goodwill é um valor decorrente de expectativas de rentabilidade futura de ativos não identificados ou não contabilizados pela empresa, tais como recursos humanos eficientes, por exemplo, devido à dificuldade de mensuração. O Chartered Institute of Management Accountants (CIMA, 1996) conceitua goodwill como a diferença de valor do negócio da empresa com os ativos avaliados pelo valor justo, ou seja, de mercado. Além disso, Dalmácio et al. (2011) argumentam que o processo de mensuração e avaliação do goodwill pode ser realizado com base em diversos instrumentos, tais como: diferença do valor dos ativos com o fluxo de benefícios futuros trazidos ao valor presente, diferença entre o valor de mercado e o valor contábil, divisão do valor de mercado com o valor contábil, "Q" de Tobim, entre outros. Somado a isso, no estudo de Ohlson (1995) sobre relevância de informações, ele utilizou o market to book, que se refere à diferença entre o valor contábil com o valor de mercado.

Por conseguinte, Kayo et al. (2006) destacam que os ativos intangíveis auxiliam na obtenção de importantes vantagens competitivas devido a sua singularidade, dificuldade de serem adquiridos e de propriedade de uma única organização. Ainda, o Comitê de Pronunciamentos Contábeis (CPC), por meio do Pronunciamento Técnico CPC 04 R1, define o ativo intangível como um ativo que não é monetário e sem substância física. Para que se reconheça um ativo é necessário o atendimento de três características fundamentais: que se tenha como identificá-lo, que se tenha controle e que gere benefício econômico futuro para a entidade.

De acordo com Lev e Daum (2003), na década de 1990, mais precisamente em seu início, percebeu-se claramente que algo de importante estava ocorrendo com as composições dos ativos nas organizações. Por meio da estatística, pode-se observar que o valor cantábil das entidades, em 1980, era cada vez menor em relação ao valor residual e ao valor de mercado. Isto se justifica do ponto de vista do mercado de capitais, pois estava ocorrendo um aumento significativo do valor dos ativos intangíveis. Neste mesmo sentido, Kayo, Teh e Basso (2006) destacam que, nos últimos anos, o interesse em pesquisas sobre os ativos intangíveis tem crescido devido a esta valorização, especialmente em relação às empresas norte-americanas.

Apenas dez anos após o início da década 1990, impulsionado pela maior divulgação de ativos intangíveis, a relação existente entre o valor dos intangíveis e o valor contábil modificouse de modo expressivo. No período entre 1982 e 1992 ocorreu uma elevação dos intangíveis de $38 \%$ para $62 \%$ com relação ao valor de mercado das ações listadas na bolsa de valores dos Estados Unidos. Este fenômeno dos ativos intangíveis fez com que os gestores, pesquisadores e executivos das organizações se interessassem pelo assunto (LEV; DAUM, 2003).

Cada vez mais se ressalta a importância dos ativos intangíveis, tanto no ambiente dos negócios quanto no meio acadêmico. Esta importância deve-se à sua influência no contexto competitivo no qual as organizações estão inseridas, e ao valor dado ao conhecimento (KAUFMANN; SCHNEIDER, 2004).

Estudos nacionais e internacionais investigaram a relação existente entre os ativos intangíveis, a criação de valor no mercado e o desempenho das empresas. No final da década de 1990, Lev e Zarowin (1999) pesquisaram a utilidade das informações financeiras e concluíram que havia um declínio da relevância do valor destas informações - especialmente do lucro e do valor do patrimônio contábil - ao longo das últimas décadas. Este enfraquecimento 
decorria principalmente do aumento dos ativos intangíveis que não eram declarados.

Perez e Famá (2006) investigaram o impacto dos ativos intangíveis não contabilizados no desempenho empresarial de modo a verificar estatisticamente a sua responsabilidade em maior geração de valor para os acionistas. Visaram comprovar se as organizações intangívelintensivas geravam mais valor quando comparadas com organizações tangível-intensivas. Os resultados da pesquisa foram significativos e mostraram que empresas com maiores parcelas de ativos intangíveis criavam mais valor para os acionistas.

Chalmers, Clinch e Godfrey (2008) investigaram a relevância de valor dos intangíveis em empresas australianas entre regimes das Normas Internacionais de Relatório Financeiro (IFRS) e normas australianas (AGAAP), respectivamente. Os resultados demonstraram que as IFRS trouxeram informações incrementais sobre o ágio para os investidores, porém não em relação aos intangíveis.

Morricone, Oriani e Sobrero (2009) analisaram se a adoção obrigatória das IFRS alterou a criação de valor dos ativos intangíveis em empresas italianas no período de 1996 a 2006 . Os resultados apontaram que após a adoção das IFRS as empresas italianas tiveram significativa diminuição na relevância do valor dos ativos intangíveis no preço das ações. Em relação à relevância do ágio, verificou-se que a adoção das IFRS teve impacto negativo.

Oliveira, Rodrigues e Craig (2010) avaliaram, nas demonstrações contábeis de 1998 a 2008, o valor identificável de ativos intangíveis, bem como o valor de ágio de todas as organizações não financeiras listadas na Bolsa de Valores Portuguesa. Além disso, examinaram o impacto da adoção formal da IAS 38 e da IFRS 3 no ano de 2005. Os resultados mostraram que o ágio relatado, o lucro líquido e outros ativos intangíveis estavam associados ao preço das ações de modo significativo. Outro aspecto que se destacou na pesquisa refere-se ao fato de que as alterações para as IAS/IFRS não impactaram na relevância do valor dos ativos intangíveis. Percebe-se que ocorreu um efeito positivo em relação à relevância do valor do ágio.

Por fim, Decker et al. (2013) analisaram a relação existente entre ativos intangíveis e a rentabilidade das empresas listadas na BM\&FBOVESPA no período de 2006 a 2011. Os resultados demonstraram que as empresas com elevada evidenciação de intangíveis apresentavam agregação de valor. Porém, ao verificar o retorno do patrimônio líquido e o retorno do ativo, as empresas com evidenciação de tangíveis intensivos tiveram melhores resultados do que as empresas com intangíveis intensivos. Os autores atribuem esses resultados a pouca evidenciação de ativos intangíveis nas demonstrações contábeis das empresas analisadas.

\subsection{Construção das Hipóteses}

A contabilidade, segundo Perez e Famá (2006), exerce influência significativa para os diversos usuários, pois promove informações precisas, transparentes e confiáveis, sendo considerada a linguagem universal dos negócios. A contabilidade possibilita aos interessados o conhecimento sobre o desempenho organizacional e sobre o patrimônio dos acionistas. De acordo com Kayo, Teh e Basso (2006), para a formação do valor econômico de uma organização os ativos intangíveis são de fundamental importância e contribuem para a obtenção de vantagens competitivas. Estes recursos auxiliam a empresa no alcance de retornos acima da média e, consequentemente, sustentam e criam valor econômico.

Lev (2001) salienta que o interesse sobre os ativos intangíveis deve-se à competição acirrada entre as organizações e o desenvolvimento de novas tecnologias, o que força as empresas a buscarem diferenciação dos seus concorrentes, exigindo mais qualidade. Conforme Perez e Famá (2006), não registrar e não mensurar os ativos intangíveis de uma organização origina diversas distorções nos relatórios contábeis. 
O Comitê de Pronunciamentos Contábeis (CPC), por meio do Pronunciamento Técnico CPC $00 \mathrm{R} 1$, postula que os relatórios financeiros possuem como objetivo geral fornecer dados contábeis e financeiros da entidade e que estas informações "sejam úteis a investidores existentes e em potencial, a credores por empréstimos e a outros credores, quando da tomada de decisão ligada ao fornecimento de recursos para a entidade". Estas decisões se referem a vender, comprar ou mesmo manter participações em instrumentos de dívida e instrumentos patrimoniais, bem como disponibilizar ou oferecer empréstimos ou outras formas de crédito.

Amir e Lev (1996) e Lev (1997) defendem que em organizações com concentração alta de ativos intangíveis, a relevância das informações contábeis de contas, como lucro e patrimônio, apresenta-se de modo limitado. Isto se deve a investimentos elevados em intangíveis, como capital humano, pesquisa e desenvolvimento e desenvolvimento de marca. Aboody e Lev (1998), Lev e Zarowin (1999) e Amir, Lev e Sougiannis (2003) destacam que deveriam ser registrados todos os gastos com intangíveis, uma vez que são relevantes para explicar o retorno e o preço das ações das organizações no mercado de capitais.

Aboody e Lev (1998) observaram evidências de que registrar todos os ativos intangíveis da empresa, de modo geral, resume e oferece dados importantes para investidores. Lev e Radhakrishnan (2003), por sua vez, concluíram que a importância do ativo intangível foi reconhecida pelos investidores e argumentam que as ineficiências ou falhas de mercado são resultados da falta de evidenciação de informações do ativo intangível das organizações.

Neste sentido, apresenta-se a primeira hipótese de pesquisa, a qual destaca que os ativos intangíveis são reconhecidos pelo mercado, sendo que sua evidenciação melhora a relevância da informação contábil.

Hipótese 1: Os ativos intangíveis estão positivamente relacionados com a relevância da informação contábil.

Há evidências de que a informação divulgada pelas empresas sobre o goodwill possui relevância de valor nos preços das ações pelo fato de não ser amortizável. O goodwill gera alterações positivas na relevância de valor, porém deve ser submetido ao teste de recuperabilidade no final do exercício empresarial. Os investidores acreditam que resultados negativos das empresas não podem ser explicados pela amortização mensal do goodwill, pela não existência de tal prática, confiando valor a este ativo intangível (OLIVEIRA; RODRIGUES; CRAIG, 2010).

Desta forma, pode-se inferir que a evidenciação do goodwill por parte das empresas ajuda a explicar a variação nos preços de suas ações, melhorando a relevância da informação contábil. Estabelece-se, assim, a hipótese 2.

Hipótese 2: O goodwill está positivamente relacionado com a relevância da informação contábil.

A relevância de valor das informações contábeis, segundo Ball e Brown (1968), é verificada principalmente pela divulgação do patrimônio líquido e do lucro líquido, em que o valor de mercado de uma empresa é consequência, essencialmente, do montante de seu patrimônio e de seus lucros. Entretanto, quando os ativos intangíveis e o valor contábil de equivalência patrimonial são diminuídos do patrimônio líquido, os investidores acreditam que estas informações não são mais tão relevantes para explicar os preços das ações (OLIVEIRA; RODRIGUES; CRAIG, 2010).

Todavia, Morricone, Oriani e Sobrero (2009) salientam a necessidade de averiguação do valor dos intangíveis como incremento informacional nas contas fundamentais da contabilidade 
das empresas, como lucro líquido e patrimônio líquido ajustado (patrimônio menos ativos intangíveis, inclusive goodwill), na relevância de valor aos investidores. Deste modo, com o intuito de averiguar a relevância da informação do patrimônio líquido menos ativos intangíveis em empresas brasileiras, formulou-se a hipótese 3.

Hipótese 3: O patrimônio líquido ajustado está positivamente relacionado com a relevância da informação contábil.

Beaver (1968) foi um dos pioneiros em analisar o conteúdo informacional da contabilidade. $\mathrm{O}$ autor teve como objetivo demonstrar que dados contábeis demonstram-se como relevantes e influenciam na expectativa de fluxos futuros de uma organização. Com o anúncio do lucro, altera-se a expectativa de retornos futuros, que resulta na reação do mercado modificando os preços das ações de acordo com as probabilidades de riscos e ganhos observados.

Nos estudos sobre a relevância da informação contábil, Ball e Brown (1968) também relacionaram os componentes contábeis, como o lucro líquido, com o valor de mercado das organizações. Os autores procuraram verificar a influência do lucro líquido no preço das ações e mostraram que o conteúdo informacional dos lucros está relacionado positivamente com os preços das ações.

O incremento informacional das perdas de impairment e despesas de amortização no lucro líquido podem auxiliar no aumento da relevância desta informação para o mercado de capitais (MORRICONE; ORIANI; SOBRERO, 2009). Deste modo, é formulada a quarta hipótese de pesquisa.

Hipótese 4: O lucro líquido ajustado está positivamente relacionado com a relevância da informação contábil.

\section{Procedimentos Metodológicos}

O presente estudo objetiva analisar a influência dos ativos intangíveis na relevância da informação contábil. Deste modo, quanto aos objetivos, o estudo caracteriza-se como descritivo, quanto aos procedimentos configura-se como documental e é quantitativo em relação à abordagem do problema.

\subsection{População e Amostra}

A população do estudo compreendeu todas as empresas listadas na Bolsa de Valores, Mercadorias e Futuros de São Paulo - BM\&FBOVESPA. A amostra correspondeu a 164 empresas, as quais foram delimitadas pela presença de informação de patrimônio e lucro líquido, quantidade e preço da ação, pois nem todas as empresas demonstraram presença de ativos intangíveis. O período de análise compreendeu os anos de 2010 a 2013 . As informações foram coletadas trimestralmente, totalizando 2.624 observações.

\subsection{Coleta e Análise dos Dados}

A coleta dos dados foi realizada por meio da base de dados Economática ${ }^{\circledR}$. Foram coletadas informações referentes ao preço das ações, quantidade das ações, ativos intangíveis, goodwill, despesas de amortização, perdas de impairment, lucro líquido e patrimônio líquido das empresas analisadas. A Tabela 1 apresenta as variáveis utilizadas no estudo. 
A influência dos ativos intangíveis na relevância da informação contábil

Tabela 1 - Variáveis da pesquisa

\begin{tabular}{|c|c|c|c|}
\hline Variável & Descrição & Coleta & Autores \\
\hline \multicolumn{4}{|c|}{ Variáveis dependentes } \\
\hline $\mathrm{P}_{\mathrm{it}+3}$ & $\begin{array}{l}\text { Preço das ações da empresa } \\
\text { três meses após o final do } \\
\text { trimestre. }\end{array}$ & Economática & $\begin{array}{l}\text { Ball e Brown (1968), Oliveira, } \\
\text { Rodrigues e Craig (2010) }\end{array}$ \\
\hline $\mathrm{P}_{\mathrm{it}+6}$ & $\begin{array}{l}\text { Preço das ações da empresa } \\
\text { seis meses após o final do } \\
\text { trimestre. }\end{array}$ & Economática & $\begin{array}{l}\text { Ball e Brown (1968), Oliveira, } \\
\text { Rodrigues e Craig (2010) }\end{array}$ \\
\hline \multicolumn{4}{|c|}{ Variáveis independentes } \\
\hline PL & $\begin{array}{l}\text { Valor contábil do } \\
\text { patrimônio líquido por ação } \\
\text { da empresa. }\end{array}$ & Economática & Ball e Brown (1968) \\
\hline LL & $\begin{array}{l}\text { Lucro líquido por ação da } \\
\text { empresa. }\end{array}$ & Economática & $\begin{array}{l}\text { Ball e Brown (1968), Oliveira, } \\
\text { Rodrigues e Craig (2010) }\end{array}$ \\
\hline PL-AI & $\begin{array}{l}\text { Valor contábil do } \\
\text { patrimônio líquido menos o } \\
\text { valor dos ativos intangíveis } \\
\text { reconhecidos (incluindo } \\
\text { goodwill) por ação da } \\
\text { empresa. }\end{array}$ & Economática & Oliveira, Rodrigues e Craig (2010) \\
\hline LL-AI & $\begin{array}{l}\text { Valor contábil do lucro } \\
\text { líquido menos as despesas } \\
\text { de amortização e as perdas } \\
\text { de impairment dos } \\
\text { intangíveis por ação da } \\
\text { empresa. }\end{array}$ & Economática & $\begin{array}{l}\text { Morricone, Oriani e Sobrero } \\
(2009)\end{array}$ \\
\hline AI & $\begin{array}{l}\text { Os ativos intangíveis } \\
\text { identificáveis por ação. }\end{array}$ & Economática & $\begin{array}{l}\text { Morricone, Oriani e Sobrero } \\
\text { (2009), Oliveira, Rodrigues e } \\
\text { Craig (2010) }\end{array}$ \\
\hline GOOD & O goodwill por ação. & Economática & $\begin{array}{l}\text { Morricone, Oriani e Sobrero } \\
\text { (2009), Oliveira, Rodrigues e } \\
\text { Craig (2010) }\end{array}$ \\
\hline
\end{tabular}

Fonte: Dados da pesquisa.

Em relação ao preço das ações, foram considerados os preços da cotação no mercado no dia do fechamento de cada trimestre (primeiro ou segundo trimestre seguinte à demonstração contábil). Caso a ação não possuísse cotação nesta data, era utilizada a última cotação imediatamente anterior. Para a delimitação do goodwill identificaram-se todas as empresas que no período analisado possuíam esta conta registrada em seus balanços patrimoniais. Entretanto, devido à baixa estimativa de empresas que possuíam esta conta registrada, utilizou-se também do ágio das empresas analisadas (CPC 04), que correspondeu ao valor de mercado delas diminuído do valor patrimonial. Também de acordo com a literatura (DALMÁCIO et al., 2011), há diversas formas de medir o goodwill e uma delas é tratar com o goodwill reconhecido na contabilidade, mas, neste caso, somente aquelas empresas que passaram por combinação de negócios vão ter este goodwill reconhecido porque o CPC 04 proíbe o reconhecimento contábil do goodwill gerado internamente. Desta forma, outra maneira é considerar o goodwill como a diferença entre o valor de mercado e o valor contábil do PL, também conhecido como Market to book - MTB. Neste segundo caso, considera-se como goodwill gerado internamente esse valor do MTB, o que permite uma análise mais ampla do goodwill, pois levou-se em consideração tanto o goodwill registrado contabilmente como aquele gerado internamente.

Com base no Quadro 1, formularam-se seis equações para a análise de regressão de dados em painel. A primeira e a segunda equações são baseadas no modelo de Ball e Brown (1968), em que se verifica a influência do patrimônio líquido e do lucro líquido no preço das ações, 
decorridos três e seis meses após o término do trimestre.

$$
\begin{aligned}
& P_{i t+3}=b_{0}+b_{1} P_{i t}+b_{2} L_{i t}+e_{i t} \\
& P_{i t+6}=b_{0}+b_{1} P_{i t}+b_{2} L_{i t}+e_{i t}
\end{aligned}
$$

A segunda e a terceira equações foram formuladas de acordo com os estudos de Morricone, Oriani e Sobrero (2009) e Oliveira, Rodrigues e Craig (2010), em que se verifica o efeito do patrimônio líquido ajustado (patrimônio menos ativos intangíveis e goodwill), lucro líquido ajustado (lucro menos perdas de impairment e despesa de amortização) e ativos intangíveis no preço das ações, após três e seis meses, respectivamente, ao término do trimestre.

$$
\begin{aligned}
& P_{i t+3}=b_{0}+b_{1} \text { PL-AI }{ }_{i t}+b_{2} L_{L}-A I_{i t}+b_{3} A_{i t}+e_{i t} \\
& P_{i t+6}=b_{0}+b_{1} \text { PL-AI }{ }_{i t}+b_{2} L_{L}-A I_{i t}+b_{3} A_{i t}+e_{i t}
\end{aligned}
$$

Por fim, a quinta e sexta equações, baseadas nos estudos de Morricone, Oriani e Sobrero (2009) e Oliveira, Rodrigues e Craig (2010), demonstram a influência do patrimônio líquido ajustado, lucro líquido ajustado e goodwill no preço das ações, três e seis meses após o término do trimestre.

$$
\begin{aligned}
& P_{i t+3}=b_{0}+b_{1} \text { PL-AI }{ }_{i t}+b_{2} L L-A I_{i t}+b_{3} G_{\text {GOOD }}{ }_{i t}+e_{i t} \\
& P_{i t+6}=b_{0}+b_{1} \text { PL-AI } I_{i t}+b_{2} L_{L}-A I_{i t}+b_{3} G_{\text {GOOD }}+e_{i t}
\end{aligned}
$$

Os dados foram analisados por meio de regressão de dados em painel com a utilização do software STATA ${ }^{\circledR}$. Também foi gerada estatística descritiva dos dados por meio do software SPSS $^{\circledR}$.

\section{Descrição e Análise dos Resultados}

Nesta seção apresenta-se a descrição e a análise dos resultados. Inicialmente, demonstrase, na Tabela 2, a estatística descritiva das variáveis utilizadas no presente estudo. Na Tabela 3 apresentam-se os testes de pressupostos para análise multivariada. Em seguida, nas Tabelas 4, 5 e 6 demonstram-se os resultados da análise de regressão de dados em painel, bem como os testes de adequação dos modelos.

Com base na Tabela 2, pode-se verificar que o valor da ação, tanto três $\left(\mathrm{P}_{i t+3}\right)$ quanto seis meses $\left(\mathrm{P}_{\mathrm{it}+6}\right)$ após o trimestre, foi mínimo de $\mathrm{R} \$ 0,027$ e máximo de $\mathrm{R} \$ 4.122,32$. Inúmeras empresas demonstraram variação de valor em relação à média de $\mathrm{R} \$ 31,46$, pois o desvio padrão demonstrou-se elevado. Percebeu-se que algumas empresas apresentaram patrimônio líquido por ação (PL) com valores negativos e máximos de $\mathrm{R} \$ 4.300,848$; a média foi de $\mathrm{R} \$ 23,9$, com desvio padrão elevado de 206,67.

O lucro líquido por ação (LL) demonstrou valor mínimo de R\$-15,12 e máximo de $\mathrm{R} \$ 21,08$, com desvio padrão $(\mathrm{R} \$ 2,13)$ superior à média $(\mathrm{R} \$ 0,89)$, o que demonstra elevada dispersão dos valores de lucro líquido entre as empresas analisadas. 
A influência dos ativos intangíveis na relevância da informação contábil

Tabela 2 - Estatística descritiva

\begin{tabular}{l|l|l|l|l}
\hline Variáveis & Mínimo & Máximo & Média & Desvio padrão \\
\hline $\mathrm{P}_{\mathrm{i}+3}$ & 0,027 & $4.122,325$ & 31,468 & 229,193 \\
\hline $\mathrm{P}_{\mathrm{i}+6}$ & 0,027 & $4.122,325$ & 32,296 & 234,682 \\
\hline $\mathrm{PL}$ & $-43,131$ & $4.300,848$ & 23,852 & 206,676 \\
\hline $\mathrm{LL}$ & $-15,129$ & 21,086 & 0,893 & 2,130 \\
\hline $\mathrm{PL}-\mathrm{AI}$ & $-46,581$ & $4.300,848$ & 19,702 & 206,983 \\
\hline LL-AI & $-11,278$ & 22,089 & 0,645 & 1,505 \\
\hline AI & 0,000 & 98,166 & 4,198 & 9,801 \\
\hline GOOD & $-1.546,934$ & $2.609,301$ & 7,965 & 105,996 \\
\hline
\end{tabular}

Fonte: Dados da pesquisa.

A média do patrimônio líquido ajustado por ação (PL-AI) foi de $\mathrm{R} \$ 19,70$ e a média do lucro líquido ajustado por ação (LL-AI) foi de $\mathrm{R} \$ 0,64$. As contas patrimônio líquido e lucro líquido por ação, quando descontadas dos ativos intangíveis e despesas de intangíveis, demonstraram redução de valor da ordem de 17,39\% e 27,77\%, respectivamente. As despesas de intangíveis reduziram em maior proporção o saldo de lucro líquido do que o ativo intangível reduziu o patrimônio líquido. No entanto, em ambos os casos pode-se notar a importância dos valores relacionados aos ativos intangíveis nessas duas variáveis contábeis (PL e LL).

Verificou-se, ainda, que algumas empresas não evidenciaram ativos intangíveis e que o valor máximo de ativo intangível por ação (AI) foi de $\mathrm{R} \$ 98,16$. O desvio padrão de $\mathrm{R} \$ 9,80$, superior à média $(\mathrm{R} \$ 4,19)$, demonstra que há uma dispersão significativa dos valores de intangíveis entre as empresas analisadas.

Quanto ao goodwill por ação (GOOD), observou-se que as empresas apresentaram valores negativos de $\mathrm{R} \$-1.546,93$ e máximos de $\mathrm{R} \$ 2.609,30$. O elevado desvio padrão (R\$ 105,996) apontou que as empresas possuem diferentes valores de goodwill em relação à média (R \$7,96). Algumas empresas, em vez de criarem valor no mercado, apresentaram perda de valor, visto o valor negativo do goodwill.

A Tabela 3 apresenta os testes de aleatoriedade, normalidade e homoscedasticidade aplicados aos dados para análise multivariada. De acordo com os testes de Durbin-Watson, Shapiro-Wilk e Levene, apresentados na Tabela 3, verificou-se que inexiste autocorrelação de primeira ordem entre os resíduos; a distribuição dos resíduos é normal e a variância dos erros é uniforme, atendendo aos pressupostos para a análise multivariada. As Tabelas 4, 5 e 6 apresentam a análise de regressão de dados em painel, relativas às equações 1 a 6 , além da adequação ao teste de LM Breusch-Pagan e Hausman, pela inserção da matriz de White.

Tabela 3 - Testes de aleatoriedade, normalidade e homoscedasticidade

\begin{tabular}{|c|c|c|}
\hline Pressupostos & Testes & Hipóteses \\
\hline \multirow{6}{*}{ 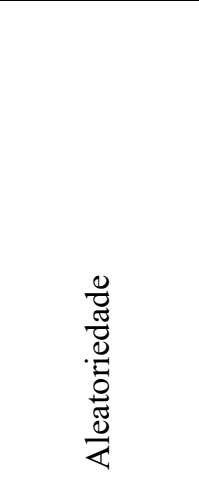 } & $\begin{array}{l}\text { (1) Durbin-Watson. Estatística } \mathrm{DW}=2,0041 \\
\text { Valor-p }=0,9453 ; \text { Autocorrelação dos resíduos }=-0,0020\end{array}$ & \multirow{6}{*}{$\begin{array}{l}\text { Inexiste } \\
\text { autocorrelação de } \\
\text { primeira ordem entre } \\
\text { os resíduos. }\end{array}$} \\
\hline & $\begin{array}{l}\text { (2) Durbin-Watson: Estatística DW }=2,0049 \\
\text { Valor-p }=0,9288 ; \text { Autocorrelação dos resíduos }=-0,0024\end{array}$ & \\
\hline & $\begin{array}{l}\text { (3) Durbin-Watson: Estatística DW }=2,0086 \\
\text { Valor-p }=0,8746 \text {; Autocorrelação dos resíduos }=-0,0043\end{array}$ & \\
\hline & $\begin{array}{l}\text { (4) Durbin-Watson: Estatística } \mathrm{DW}=2,0087 \\
\text { Valor-p }=0,8727 \text {; Autocorrelação dos resíduos }=-0,0044\end{array}$ & \\
\hline & $\begin{array}{l}\text { (5) Durbin-Watson: Estatística DW }=1,9711 \\
\text { Valor-p = 0,4189; Autocorrelação dos resíduos }=0,0144\end{array}$ & \\
\hline & $\begin{array}{l}\text { (6) Durbin-Watson: Estatística } \mathrm{DW}=1,8015 \\
\text { Valor-p }=0,0000 ; \text { Autocorrelação dos resíduos }=0,0992\end{array}$ & \\
\hline
\end{tabular}




\begin{tabular}{|c|c|c|}
\hline Pressupostos & Testes & Hipóteses \\
\hline \multirow{6}{*}{ 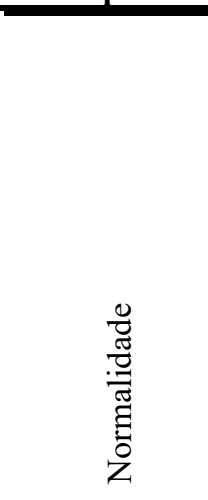 } & $\begin{array}{l}\text { (1) Shapiro-Wilk: } \\
\text { Estatística } S W=0,1108 \text {; Valor-p }=0,0000\end{array}$ & \multirow{6}{*}{$\begin{array}{l}\text { A distribuição dos } \\
\text { resíduos é normal. }\end{array}$} \\
\hline & $\begin{array}{l}\text { (2) Shapiro-Wilk: } \\
\text { Estatística } S W=0,1060 ; \text { Valor-p }=0,0000\end{array}$ & \\
\hline & $\begin{array}{l}\text { (3) Shapiro-Wilk: } \\
\text { Estatística } S W=0,1169 \text {; Valor-p }=0,0000\end{array}$ & \\
\hline & $\begin{array}{l}\text { (4) Shapiro-Wilk: } \\
\text { Estatística } \mathrm{SW}=0,1107 \text {; Valor-p }=0,0000\end{array}$ & \\
\hline & $\begin{array}{l}\text { (5) Shapiro-Wilk: } \\
\text { Estatística } \mathrm{SW}=0,2413 \text {; Valor-p }=0,0000\end{array}$ & \\
\hline & $\begin{array}{l}\text { (6) Shapiro-Wilk: } \\
\text { Estatística } \mathrm{SW}=0,5915 \text {; Valor-p }=0,0000\end{array}$ & \\
\hline \multirow{6}{*}{ 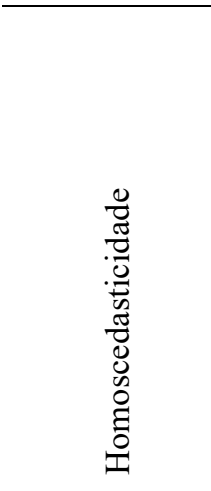 } & $\begin{array}{l}\text { (1) Levene: } \\
\text { Estatística } \mathrm{F}=1,4587 ; \text { Valor-p }=0,2273\end{array}$ & \multirow{6}{*}{$\begin{array}{l}\text { A variância dos erros } \\
\text { é uniforme. }\end{array}$} \\
\hline & $\begin{array}{l}\text { (2) Levene: } \\
\text { Estatística } F=1,5052 ; \text { Valor-p }=0,2200\end{array}$ & \\
\hline & $\begin{array}{l}\text { (3) Levene: } \\
\text { Estatística } \mathrm{F}=1,3872 \text {; Valor-p }=0,2390\end{array}$ & \\
\hline & $\begin{array}{l}\text { (4) Levene: } \\
\text { Estatística } F=1,4470 ; \text { Valor-p }=0,2291\end{array}$ & \\
\hline & $\begin{array}{l}\text { (5) Levene: } \\
\text { Estatística } \mathrm{F}=0,3444 \text {; Valor-p }=0,5574\end{array}$ & \\
\hline & $\begin{array}{l}\text { (6) Levene: } \\
\text { Estatística } \mathrm{F}=3,0527 \text {; Valor- } \mathrm{p}=0,0807\end{array}$ & \\
\hline
\end{tabular}

Fonte: Dados da pesquisa.

Pode-se verificar, de acordo com a Tabela 4, que as equações 1 e 2 rejeitaram a adequação do modelo de dados em painel POLS pela apresentação de hipótese nula no teste de LM Breusch-Pagan. Já o teste de Hausman rejeitou a correção de erros do modelo de efeito aleatório em favor do modelo de efeitos fixos. Desta forma, ambas as equações correspondem à utilização dos resultados do modelo de efeitos fixos.

Tabela 4 - Análise de regressão de dados em painel - equações 1 e 2

\begin{tabular}{|c|c|c|c|c|c|}
\hline \multicolumn{3}{|c|}{$\begin{array}{l}\text { Sumário da equação } 1 \\
\left(P_{i t+3)}\right.\end{array}$} & \multicolumn{3}{|c|}{$\begin{array}{l}\text { Sumário da equação } 2 \\
\left(P_{i t+6)}\right.\end{array}$} \\
\hline Variáveis & Coef. & $\mathbf{P}>|\mathbf{z}|$ & Variáveis & Coef. & $\mathbf{P}>|\mathbf{z}|$ \\
\hline (Constante) & 21,96051 & 0,000 & (Constante) & 27,17844 & 0,000 \\
\hline PL & 0,3596864 & $0,007 *$ & PL & 0,1752859 & 0,155 \\
\hline $\mathrm{LL}$ & 1,017959 & $0,000 *$ & LL & 1,011451 & $0,000 *$ \\
\hline LM Breusch-Pagan: & \multicolumn{2}{|l|}{0,0000} & LM Breusch-Pagan: & \multicolumn{2}{|l|}{0,0000} \\
\hline Hausman: & \multicolumn{2}{|l|}{0,0000} & Hausman: & \multicolumn{2}{|l|}{0,0000} \\
\hline $\mathrm{R}^{2}:$ & \multicolumn{2}{|l|}{0,2763} & $\mathrm{R}^{2}$ : & \multicolumn{2}{|l|}{0,0821} \\
\hline Prob > chi2: & \multicolumn{2}{|l|}{0,0000} & Prob > chi2: & \multicolumn{2}{|l|}{0,0000} \\
\hline
\end{tabular}

* significativo a $1 \%$. ** significativo a $5 \%$.

Fonte: Dados da pesquisa.

Em relação ao sumário da equação 1, pode-se verificar a explicação do modelo de 0,2763 $\left(\mathrm{R}^{2}\right)$ e significância a $1 \%($ Prob $>$ chi2 $=0.0000)$. A equação 2 demonstrou $\mathrm{R}^{2}$ de 0,0821 e Prob $>$ chi2 $=0.0000$. Portanto, o modelo perde poder explicativo com o passar do tempo. Quanto à significância das variáveis, constatou-se que o patrimônio líquido (PL) apresenta influência positiva e significativa nos preços das ações três meses após o término do trimestre $\left(\mathrm{P}_{\mathrm{i} t+3}\right)$, enquanto o lucro líquido (LL) mostrou efeito positivo e significativo no preço das ações três $\left(\mathrm{P}_{\mathrm{it}+3}\right)$ e seis $\left(\mathrm{P}_{\mathrm{it}+6}\right)$ meses após o encerramento do trimestre anterior. 
Desta forma, infere-se que as informações sobre o lucro líquido e o patrimônio líquido apresentam relevância para o mercado de capitais. O lucro líquido apresenta-se relevante para o mercado de capitais em ambos os períodos (três e seis meses após a publicação da informação). O patrimônio líquido, no entanto, perde poder explicativo com o passar do tempo, sendo relevante apenas três meses após a publicação dos relatórios financeiros. A Tabela 5 demonstra a análise de regressão de dados em painel das equações 3 e 4 .

Tabela 5 - Análise de regressão de dados em painel - equações 3 e 4

\begin{tabular}{|c|c|c|c|c|c|}
\hline \multicolumn{3}{|c|}{$\begin{array}{l}\text { Sumário da equação } 3 \\
\left(P_{i t+3)}\right.\end{array}$} & \multicolumn{3}{|c|}{$\begin{array}{l}\text { Sumário da equação } 4 \\
\left(P_{i t+6)}\right.\end{array}$} \\
\hline Variáveis & Coef. & $\mathbf{P}>|\mathbf{z}|$ & Variáveis & Coef. & $\mathbf{P}>|\mathbf{z}|$ \\
\hline (Constante) & 22,59113 & 0,000 & (Constante) & 27,51941 & 0,000 \\
\hline PL-AI & 0,3595487 & $0,007 *$ & PL-AI & 0,1752444 & 0,155 \\
\hline LL-AI & 1,011264 & $0,017 *$ & LL-AI & 0,9418239 & $0,007 *$ \\
\hline AI & 0,271007 & $0,003 *$ & AI & 0,168154 & $0,043 *$ \\
\hline LM Breusch-Pagan: & \multicolumn{2}{|l|}{0,0000} & LM Breusch-Pagan: & \multicolumn{2}{|l|}{0,0000} \\
\hline Hausman: & \multicolumn{2}{|l|}{0,0000} & Hausman: & \multicolumn{2}{|l|}{0,0000} \\
\hline $\mathrm{R}^{2}:$ & \multicolumn{2}{|l|}{0,2754} & $\mathrm{R}^{2}:$ & \multicolumn{2}{|l|}{0,0816} \\
\hline Prob > chi2: & \multicolumn{2}{|l|}{0,0000} & Prob > chi2: & \multicolumn{2}{|l|}{0,0001} \\
\hline
\end{tabular}

* significativo a $1 \%$. ** significativo a $5 \%$.

Fonte: Dados da pesquisa.

Com base na Tabela 5, pode-se verificar a rejeição do modelo de dados em painel POLS (LM Breusch-Pagan) e de correção de erros pelo efeito aleatório (Hausman) nas equações 3 e 4. Deste modo, analisaram-se os resultados oriundos do modelo de efeitos fixos.

Observou-se, em relação à equação 3 , que o $\mathrm{R}^{2}$ foi de 0,2754 e a significância do modelo de $1 \%$ (Prob $>$ chi $2=0.0000)$, enquanto na equação $4 \mathrm{o} \mathrm{R}^{2}$ foi de 0,0816 e significância de $1 \%$ (Prob $>$ chi $2=0.0001)$. Assim como na Tabela 3, nota-se uma redução no poder explicativo do modelo com o passar do tempo (de três para seis meses).

As variáveis lucro líquido ajustado (LL-AI) e ativo intangível (AI) apresentaram significância e influência positiva no preço das ações três $\left(\mathrm{P}_{i t+3}\right)$ e seis $\left(\mathrm{P}_{\mathrm{it}+6}\right)$ meses após a publicação das informações do trimestre. Já o patrimônio líquido ajustado (PL-AI) apresentou efeito significativo e positivo no preço das ações apenas três meses $\left(\mathrm{P}_{\mathrm{it}+3}\right)$ após a publicação das informações. Assim como nos modelos anteriores (equações 1 e 2), o PL perdeu poder explicativo com o passar do tempo. A Tabela 6 demonstra a análise de regressão de dados em painel das equações 5 e 6 .

Tabela 6 - Análise de regressão de dados em painel - equações 5 e 6

\begin{tabular}{|c|c|c|c|c|c|}
\hline \multicolumn{3}{|c|}{$\begin{array}{l}\text { Sumário da equação } 5 \\
\left(P_{i t+3)}\right.\end{array}$} & \multicolumn{3}{|c|}{$\begin{array}{l}\text { Sumário da equação } 6 \\
\left(P_{i t+6)}\right.\end{array}$} \\
\hline Variáveis & Coef. & $\mathbf{P}>|\mathbf{z}|$ & Variáveis & Coef. & $\mathbf{P}>|\mathbf{z}|$ \\
\hline (Constante) & 2,558808 & 0,036 & (Constante) & 4,486647 & 0,000 \\
\hline PL-AI & 1,092243 & $0,000 *$ & PL-AI & 0,9961143 & $0,000 *$ \\
\hline LL-AI & 0,4488654 & $0,063 * *$ & LL-AI & 0,2714403 & $0,005^{*}$ \\
\hline GOOD & 0,8895004 & $0,000 *$ & GOOD & 0,9964234 & $0,000 *$ \\
\hline LM Breusch-Pagan: & \multicolumn{2}{|l|}{0,0000} & LM Breusch-Pagan: & \multicolumn{2}{|l|}{0,0000} \\
\hline Hausman: & \multicolumn{2}{|l|}{$-13,13$} & Hausman: & \multicolumn{2}{|l|}{$-0,82$} \\
\hline $\mathrm{R}^{2}:$ & \multicolumn{2}{|l|}{0,8619} & $\mathrm{R}^{2}:$ & \multicolumn{2}{|l|}{0,9961} \\
\hline Prob > chi2: & \multicolumn{2}{|l|}{0,0000} & Prob > chi2: & \multicolumn{2}{|l|}{0,0000} \\
\hline
\end{tabular}

* significativo a $1 \%$. ** significativo a $5 \%$.

Fonte: Dados da pesquisa.

De acordo com o exposto na Tabela 6, o teste de LM Breusch-Pagan rejeitou a adequação 
das equações 5 e 6 ao modelo de dados em painel POLS. O teste de Hausman, por demonstrar valores de -13,13 (equação 5) e -0,82 (equação 6), não foi eficaz na definição do modelo a ser utilizado ao confrontar os dados do modelo de efeitos fixos e o de efeitos aleatórios. Desta forma, optou-se por utilizar os resultados do modelo de efeitos fixos, conforme observado no teste das demais equações.

Verificou-se que a explicação do modelo foi de 0,86 (equação 5), 0,99 (equação 6), com significância a $1 \%$ (Prob $>$ chi2 $=0.0000)$ para ambas as equações. Em relação aos coeficientes das variáveis, observou-se que o patrimônio líquido ajustado (PL-AI), o lucro líquido ajustado (LL-AI) e o goodwill (GOOD) apresentaram relação positiva e significativa com o preço das ações três meses $\left(\mathrm{P}_{\mathrm{it}+3}\right)$ e seis meses $\left(\mathrm{P}_{\mathrm{it}+6}\right)$ após o encerramento do trimestre.

Dado o exposto, pode-se constatar que a divulgação de informações sobre ativos intangíveis e goodwill apresenta relevância para o mercado de capitais, impactando o preço das ações até seis meses após a publicação dos relatórios financeiros. Além disso, a inclusão do goodwill no modelo, além de melhorar o poder explicativo do modelo como um todo, melhorou o poder de explicação do PL, que nos modelos anteriores (equações 2 e 4) não era significativo em relação ao preço da ação seis meses após o trimestre.

Assim, foram aceitas as hipóteses 1 e 2, as quais tratavam da relevância significativa dos ativos intangíveis e do goodwill, respectivamente, para o mercado de capitais. Este resultado corrobora o defendido por Kayo, Teh e Basso (2006) que, para a formação do valor econômico de uma organização, os ativos intangíveis são de fundamental importância e contribuem para a obtenção de vantagens competitivas. Todos os gastos com ativos intangíveis devem ser registrados, pois são relevantes e impactam o preço das ações das organizações (ABOODY; LEV, 1998; LEV; ZAROWIN, 1999; AMIR; LEV; SOUGIANNIS, 2003).

Em relação ao goodwill, os resultados deste estudo corroboram os achados de Oliveira, Rodrigues e Craig (2010), para os quais o goodwill é considerado como uma informação relevante e que impacta o preço das ações pelo fato de não sofrer amortização, gerando alterações positivas na relevância de valor.

Quanto às variáveis lucro líquido e lucro líquido ajustado, observou-se que elas apresentaram relevância para o mercado de capitais, tanto três quanto seis meses depois de publicadas as informações. O patrimônio líquido apresentou relevância para o mercado até três meses depois de publicadas as informações. Já o patrimônio líquido ajustado demonstrou relevância tanto três quanto seis meses depois de divulgadas as demonstrações financeiras. Desse modo, as hipóteses 3 e 4 do estudo foram aceitas.

Para Ball e Brown (1968), a relevância da informação contábil é verificada principalmente pela publicação do patrimônio e do lucro líquido, impactando o valor de mercado da empresa. Quanto ao patrimônio líquido ajustado e ao lucro líquido ajustado pelos ativos e despesas de ativos intangíveis, segundo Morricone, Oriani e Sobrero (2009), infere-se que estes impactam o preço das ações pelo incremento informacional de intangíveis em contas fundamentais, como patrimônio e lucro.

\section{Considerações Finais}

Este estudo teve por objetivo analisar a influência dos ativos intangíveis na relevância da informação contábil. A metodologia utilizada caracterizou-se como descritiva, documental e quantitativa. A amostra do estudo foi constituída por 164 empresas listadas na BM\&FBOVESPA no período de 2010 a 2013. Para a análise dos dados utilizou-se de regressão de dados em painel e descrição das variáveis, por meio dos softwares STATA e SPSS. Para a consecução do objetivo proposto foram desenvolvidas quatro hipóteses relacionadas à influência das variáveis ativo intangível, goodwill, patrimônio líquido ajustado e lucro líquido 
ajustado na relevância da informação contábil, respectivamente.

De maneira geral, constatou-se que todas as variáveis em análise apresentaram influência positiva no preço das ações, podendo-se afirmar que representam informações relevantes para o mercado. No entanto, o PL perde poder explicativo com o passar do tempo, não sendo relevante estatisticamente em relação ao preço das ações seis meses após a publicação dos relatórios financeiros.

Todavia, observou-se que quando o PL é ajustado pelos ativos intangíveis, e também a variável goodwill é incluída no modelo de análise, o valor do PL ajustado é significativo em ambos os períodos. Conclui-se, assim, que a inclusão dos ativos intangíveis e do goodwill na análise de value relevance da informação não só melhora o poder explicativo das informações contábeis de maneira geral, como aumenta o poder explicativo do PL individualmente.

Com base nos resultados do estudo, foi possível aceitar as quatro hipóteses de pesquisa ao se verificar a influência positiva e significativa de ativo intangível, goodwill, patrimônio líquido ajustado e lucro líquido ajustado no preço das ações, além das contas fundamentais como patrimônio e lucro. Os resultados deste estudo contribuem com a literatura internacional sobre o tema relevância da informação contábil (BALL; BROWN, 1968; ABOODY; LEV, 1998; LEV; ZAROWIN, 1999; AMIR; LEV; SOUGIANNIS, 2003; MORRICONE; ORIANI; SOBRERO, 2009; OLIVEIRA; RODRIGUES; CRAIG, 2010) ao trazer evidências empíricas de empresas localizadas em mercado emergente, de que o ativo intangível, o goodwill, o patrimônio líquido, o lucro líquido e o patrimônio e o lucro líquido ajustado por intangíveis estão relacionados positivamente com o preço das ações. Desta forma, verifica-se a importância do reconhecimento e da evidenciação de ativos intangíveis, inclusive o goodwill, visto que auxiliam as empresas a criarem valor no mercado que, por sua vez, pode influenciar a opinião de agentes econômicos e a tomada de decisão quanto a investimentos futuros despendidos pela empresa.

Tais resultados ressaltam a importância de as empresas atenderem as prerrogativas de normas contábeis quanto ao reconhecimento e divulgação tanto de ativos intangíveis adquiridos ou gerados internamente quanto da fase de desenvolvimento, e também do valor pago a mais do que o de mercado em uma combinação de negócio conhecida por goodwill. Observou-se, no atual estudo, a incipiência de empresas que registraram o goodwill quando da aquisição de uma combinação de negócios, o que impactou na necessidade de análise do MTB, sendo que ele se apresentou com valor expressivo para as empresas, demonstrando que elas possuem maior valor de mercado do que contábil.

Neste sentido, as empresas que reconhecem tais contas, quando permitido em lei, têm a possibilidade de aumento do preço de suas ações no mercado devido ao aumento de seus ativos. Este fenômeno ocorre devido à análise de investidores de mercado de informações contábeis das empresas, considerados os ativos intangíveis com base em evidências do atual estudo como uma informação relevante de análise de tais investidores, para a tomada de decisão de compra ou venda de ações das empresas. Por conseguinte, infere-se que empresas que divulgarem ativos intangíveis podem ter maior retorno de suas ações, valor de mercado, bem como possibilidade de recebimento de investimentos de novos acionistas.

Como limitações da presente pesquisa pode-se apontar a falta de empresas que divulgam informações referentes aos ativos intangíveis e ao goodwill, restringindo a amostra. Outra limitação do estudo refere-se a não utilização de janela de evento considerando a data da divulgação da demonstração financeira de cada empresa individualmente. Utilizou-se como data base para coleta do preço das ações a última cotação do trimestre seguinte (equações 1, 3 e 5) ou de dois trimestres seguintes (equações 2, 4 e 6) para todas as empresas, o que limita a análise do efeito da divulgação da informação contábil sobre o preço das ações. De todo modo, acredita-se que tais limitações não invalidam os resultados encontrados. 
Sugere-se para pesquisas futuras a utilização de outros modelos para verificar a relevância de outras informações ou variáveis contábeis para o mercado de capitais, além dos ativos intangíveis.

\section{Referências}

ABOODY, D.; LEV, B. The value relevance of intangibles: The case of software capitalization. Journal of Accounting Research, v. 36, p. 161-191, 1998. DOI: $10.2307 / 2491312$.

AMIR, E.; LEV, B. Value-relevance of nonfinancial information: The wireless communications industry. Journal of Accounting and Economics, v. 22, n. 1, p. 3-30, 1996. http://dx.doi.org/10.1016/S0165-4101(96)00430-2.

; LEV, B.; SOUGIANNIS, T. Do financial analysts get intangibles? European

Accounting Review, v. 12, n. 4, p. 635-659, 2003.

http://dx.doi.org/10.1080/0963818032000141879.

ANTUNES, G. A. et al. Efeitos da adesão aos níveis de governança da bolsa de valores de São Paulo na qualidade da informação contábil. ASAA-Advances in Scientific and Applied Accounting, v. 3, n. 1, p. 109-138, 2010.

BALL, R.; BROWN, P. An empirical evaluation of accounting income numbers. Journal of Accounting Research, v.6, n.2, p. 159-178, 1968. DOI: 10.2307/2490232.

BARTH, M. E.; BEAVER, W. H.; LANDSMAN, W. R. The relevance of the value relevance literature for financial accounting standard setting: Another view. Journal of Accounting and Economics, v. 31, n. 1, p. 77-104, 2001. http://dx.doi.org/10.1016/S01654101(01)00019-2.

BEAVER, W. H. The information content of annual earnings announcements. Journal of accounting research, v.6, p. 67-92, 1968. DOI: 10.2307/2490070.

BEISLAND, L. A.; HAMBERG, M. Earnings sustainability, economic conditions and the value relevance of accounting information. Scandinavian Journal of Management, v. 29, n. 3, p. 314-324, 2013. http://dx.doi.org/10.1016/j.scaman.2013.02.001.

CHALMERS, K.; CLINCH, G.; GODFREY, J. M. Adoption of international financial reporting standards: Impact on the value relevance of intangible assets. Australian Accounting Review, v. 18, n. 3, p. 237-247, 2008. DOI: 10.1111/j.1835-2561.2008.0028.x

CIMA - THE CHARTERED INSTITUTE OF MANAGEMENT TERMINOLOGY.

Management accounting official terminology. London: Chartered Institute of Management Accountants, 114 p., 1996.

CPC 00 (R1). Pronunciamento Conceitual Básico. Comitê de Pronunciamentos Contábeis, p. 1-35, 2010, recuperado em:

$<$ http://static.cpc.mediagroup.com.br/Documentos/147_CPC00_R1.pdf> 
CPC 04 (R1). Ativo Intangível. Comitê de Pronunciamentos Contábeis, p. 1-41, 2010, recuperado em:

$<$ http://static.cpc.mediagroup.com.br/Documentos/187_CPC_04_R1_rev\%2008.pdf $>$

CPC 15 (R1). Combinação de Negócios. Comitê de Pronunciamentos Contábeis, p. 1-70, 2010, recuperado em:

$<$ http://static.cpc.mediagroup.com.br/Documentos/235_CPC15R1_rev_06.pdf $>$

DALMÁCIO, F. Z. et al. A relevância do goodwill no processo de avaliação das empresas brasileiras. Base, v. 8, n. 4, p. 359-372, 2011. DOI: 10.4013/base.2011.84.07.

DECHOW, P.; GE, W.; SCHRAND, C. Understanding earnings quality: A review of the proxies, their determinants and their consequences. Journal of Accounting and Economics, v. 50, n. 2, p. 344-401, 2010. http://dx.doi.org/10.1016/j.jacceco.2010.09.001.

DECKER, F.; ENSSLIN, S. R.; REINA, D. R. M.; REINA, D. A Relação entre os ativos intangíveis e a rentabilidade das ações: Um estudo com empresas listadas no índice Bovespa. REUNA, v. 18, n. 4, p. 75-92, 2013.

FASB - FINANCIAL ACCOUNTING STANDARDS BOARD. Statement of financial accounting concepts $n$. 5. Recognition and measurement in financial statements of business enterprises. Stanford, Connecticut, 1984.

HENDRIKSEN, E. S.; VAN BREDA, M. Teoria da contabilidade. São Paulo: Atlas, 1999.

HOLTHAUSEN, R. W.; WATTS, R. L. The relevance of the value-relevance literature for financial accounting standard setting. Journal of Accounting and Economics, v. 31, n. 1, p. 3-75, 2001. http://dx.doi.org/10.1016/S0165-4101(01)00029-5.

IUDÍCIBUS, S. Teoria da contabilidade. 6. ed. São Paulo: Atlas, 2000.

KAPLAN, R. S.; NORTON, D. P. A estratégia em ação: balanced scorecard. Rio de Janeiro: Campus, 1997.

KAUFMANN, L.; SCHNEIDER, Y. Intangibles: a synthesis of current research. Journal of Intellectual Capital, v. 5, n. 3, p. 366-388, 2004.

http://dx.doi.org/10.1108/14691930410550354.

KAYO, E. K. A estrutura de capital e o risco das empresas tangível e intangívelintensivas: uma contribuição ao estudo da valoração de empresas. 2002. 126 f. Tese (Doutorado em Administração), Departamento de Administração da Faculdade de Economia, Administração e Contabilidade, Universidade de São Paulo, São Paulo.

KAYO, E. K. et al. Ativos intangíveis, ciclo de vida e criação de valor. Revista de Administração Contemporânea, v. 10, n. 3, p. 73-90, 2006. http://dx.doi.org/10.1590/S1415-65552006000300005.

; TEH, C. C.; BASSO, L. F. C. Ativos intangíveis e estrutura de capital: a influência das marcas e patentes sobre o endividamento. Revista de Administração, v. 41, n. 2, p. 158- 
$168,2006$.

LEV, B. Intangibles: management and reporting. Washington: Brookings, 2001.

The boundaries of financial reporting and how to extend them. Journal of Accounting Research, v. 37, n. 2, p. 353-385, 1997. DOI:

http://dx.doi.org/10.2469/dig.v30.n3.702.

; DAUM, J. H. Intangible assets and the need for a holistic and more future-oriented approach to enterprise management and corporate reporting. In: First PMA Intellectual Capital Research Symposium, Cranfield, Royaume-Uni, 2003.

; RADHAKRISHNAN, S. The measurement of firm-specific organization capital. National Bureau of Economic Research, NBER, Working Paper n. 9581, March 2003. DOI: 10.3386/w9581.

; ZAROWIN, P. The Boundaries of financial reporting and how to extend them (Digest Summary). Journal of Accounting Research, v. 37, n. 2, p. 353-385, 1999. http://dx.doi.org/10.2469/dig.v30.n3.702.

MACEDO, M. A. S.; MACHADO, M. A. V.; MACHADO, M. R. Análise da relevância da informação contábil no Brasil num contexto de convergência às normas internacionais de contabilidade. Revista Universo Contábil, v. 9, n. 1, p. 65-85, 2013.

DOI:10.4270/ruc.2013104.

MONOBE, M. Contribuição à mensuração e contabilização do goodwill não adquirido. 183 f. Tese de Doutorado. Doutorado Faculdade de Economia, Administração e Contabilidade da Universidade de São Paulo, São Paulo, 1986.

MORRICONE, S.; ORIANI, R.; SOBRERO, M. The value relevance of intangible assets and the mandatory adoption of IFRS. Disponível em:

$<$ http://papers.ssrn.com/sol3/papers.cfm?abstract_id=1600725>. Acesso em: 30 jan. 2015.

OHLSON, J. A. Earnings, book values, and dividends in equity valuation. Contemporary Accounting Research, v. 11, n.2 , p. 661-687, 1995. DOI: 10.1111/j.19113846.1995.tb00461.x

OLIVEIRA, L.; RODRIGUES, L. L.; CRAIG, R. Intangible assets and value relevance: Evidence from the Portuguese stock exchange. The British Accounting Review, v. 42, n. 4, p. 241-252, 2010. http://dx.doi.org/10.1016/j.bar.2010.08.001.

PEREZ, M. M.; FAMÁ, R. Ativos intangíveis e o desempenho empresarial. Revista Contabilidade e Finanças, v. 17, n. 40, p. 7-24, 2006. http://dx.doi.org/10.1590/S151970772006000100002.

SILVA, A. F.; MACEDO, M. A. S.; MARQUES, J. A. V. C. Análise da relevância da informação contábil no setor brasileiro de energia elétrica no período de 2005 a 2007: uma discussão com foco nas variáveis II, FCO e EBITDA. Revista Universo Contábil, v. 8, n. 2, p. 6-24, 2012. DOI:10.4270/RUC.2012210. 
UPTON, W. S. Business and financial reporting, challenges from the new economy. Fnancial Accounting Series - Special Report. FASB. USA, 2001. Disponível em: http://www.fasb.org/articles\&reports/sr_new_economy.pdf. Acesso em: 30 nov. 2014. 